\title{
The United Kingdom's specialist workforce in paediatric dentistry: current and future trends
}

\author{
M. L. Hunter, ${ }^{1}$ L. E. Harrhy² and M. Z. Morgan ${ }^{3}$
}

\begin{abstract}
Objective To provide information relevant to the current and predicted future profile of the UK's specialist workforce in paediatric dentistry. Design Postal questionnaire. Subjects Two hundred and twenty-one registered dentists whose names appeared on the Specialist List in Paediatric Dentistry and who were identified as resident within the United Kingdom.

Results Questionnaires were returned by 192 specialists, a response rate of $86.9 \%$. This paper is, however, based on data provided by 187 respondents currently practising in the United Kingdom (54 (28.9\%) male and 133 (71.1\%) female). The majority of respondents were based in England (138) and practised in hospital settings (120). Eighty-two respondents (14 males and 68 females) stated that they were working part-time and 57 ( 5 males and 52 females) indicated that they had already taken a break at some time during their career. Eighty-four (45.2\%) respondents plan to retire during the next ten years. Conclusions Working patterns associated with a feminised workforce will have a considerable impact on the volume of service that can be provided. Workforce planners must be cognisant of the need to increase the number of specialists in training to take account of service lost through part-time working and career breaks.
\end{abstract}

\section{INTRODUCTION}

Specialists in paediatric dentistry have specialised knowledge and skills in the oral and dental care of children, including those who are anxious or who have special medical or dental needs. They are able to accept referral of, and provide care for many of the children whom general dental practitioners are unable to treat; they are also able to contribute to service development within their locality. Those in universities and the salaried services are often involved in the teaching of dental students, trainee specialists, other dental care professionals and professionals allied to medicine.

Immediately following the General Dental Council's (GDC's) recognition of

\footnotetext{
1"Professor and Honorary Consultant in Paediatric Dentistry, ${ }^{3}$ Lecturer in Dental Public Health, Applied Clinical Research and Public Health, Cardiff University, School of Dentistry, Heath Park, Cardiff, CF14 4XY; ${ }^{2}$ General Dental Practitioner, Dental Surgery, 1st Floor, Tannery Building, Bridge Street, Brecon, Powys, LD3 8AH ${ }^{*}$ Correspondence to: Professor Margaret L. Hunter Email: hunterml@cardiff.ac.uk
}

\section{Refereed Paper}

Accepted 25 March 2010

DOI: $10.1038 /$ sj.bdj.2010.499

${ }^{\circledR}$ British Dental Journal 2010; 208: 559-562 paediatric dentistry as a United Kingdom (UK) dental specialty on 1 July 1998, a transitional ('grand-parenting') period of two years permitted registered dentists other than those who had completed Specialty Advisory Committee (SAC) approved training to gain admittance to its Specialist List. By the end of this period, approximately 200 registered dentists had, by virtue of having met certain minimum criteria, been given the right to call themselves specialists in paediatric dentistry. Since 1 July 2000, entry to the Specialist List in Paediatric Dentistry has been restricted to those who have completed three years' full-time (or its part-time equivalent) training leading to the award of a Certificate of Completion of Specialist Training (CCST) or been granted 'mediated' entry on the basis of specialist dental qualifications awarded outside the UK and/or knowledge and experience derived from academic and research work.

While the concept of specialisation in dentistry has been based upon specialist dental practice, paediatric dentistry is one of the dental specialties recognised as being consultant-led. Consultants in paediatric dentistry train for a further two years post-CCST; this additional training is mainly hospital and paediatrics orientated and produces an individual who is able to integrate and liaise with paediatric medical, surgical and anaesthetic consultants in the holistic care of child patients.

Between 1 July 2000 and the present, a fortuitous imbalance between the number of individuals leaving and entering the Specialist List has allowed a slow but steady growth in the specialist workforce. Crucially, however, this has occurred at a time which has been marked by a significant change in the gender balance of the dental profession in the UK: at the time of writing, females make up 40\% of GDC registrants $(14,501$ females compared with 21,780 males). ${ }^{1}$ Against this background, if we are to ensure that we meet the needs of the UK's child population in relation to access to specialist services in paediatric dentistry, workforce planning requires rather more precise data than currently available. This study, therefore, sought to provide information relevant to the current and predicted future profile of the UK's specialist workforce in paediatric dentistry. 


\section{MATERIAL AND METHODS}

In the autumn of 2008, the names and registered details of 234 dentists entitled to use the title 'Specialist in Paediatric Dentistry' was obtained by reference to the relevant Specialist List held by the GDC. Of these, 221 individuals were identified as resident within the UK and were included in the study.

A postal questionnaire, comprising nine 'closed' and two 'open' questions, was developed for data collection. Closed questions were used to examine the following:

- Demographic characteristics (gender, age)

- Geographic location and clinical setting of specialist practice

- Employment status (full/part-time; consultant/non-consultant)

- Career breaks and retirement plans.

The subsidiary open questions were used to provide additional information relating to part-time working and career breaks. Before its commencement, it was established that the study did not require ethical approval as it constituted a service evaluation.

Each eligible specialist in paediatric dentistry was sent a copy of the questionnaire and a stamped addressed envelope for its return. An explanatory letter was also included. In order to allow the identification of non-respondents, each questionnaire was coded but to ensure anonymity, the code-break was kept by a third party not directly involved in the analysis of the responses.

A week after the initial deadline for receipt of responses, a second mailing was targeted at those who had thus far failed to return questionnaires. The original covering letter and questionnaire were included, together with a second covering letter and postage-paid, self-addressed envelope. The second covering letter informed the recipient of the existing response rate and set a deadline approximately two weeks distant. At the end of this period, data were entered into Microsoft Excel XP for analysis.

\section{RESULTS}

Questionnaires were returned by 192 specialists in paediatric dentistry, a response rate of $86.9 \%$. Five specialists, however, returned blank questionnaires as they had

\section{Table 1 Planned retirement dates of UK specialists and consultants in paediatric dentistry}

\begin{tabular}{|l|l|l|}
\hline Year of planned retirement & $\begin{array}{l}\text { Number of specialists } \\
(n=186)\end{array}$ & $\begin{array}{l}\text { Number of consultants } \\
(n=65)\end{array}$ \\
\hline 2009 & 13 & 4 \\
\hline $2010-2014$ & 31 & 9 \\
\hline $2015-2019$ & 40 & 10 \\
\hline $2020-2024$ & 43 & 17 \\
\hline $2025-2029$ & 21 & 10 \\
\hline 2030 or later & 38 & 15 \\
\hline
\end{tabular}

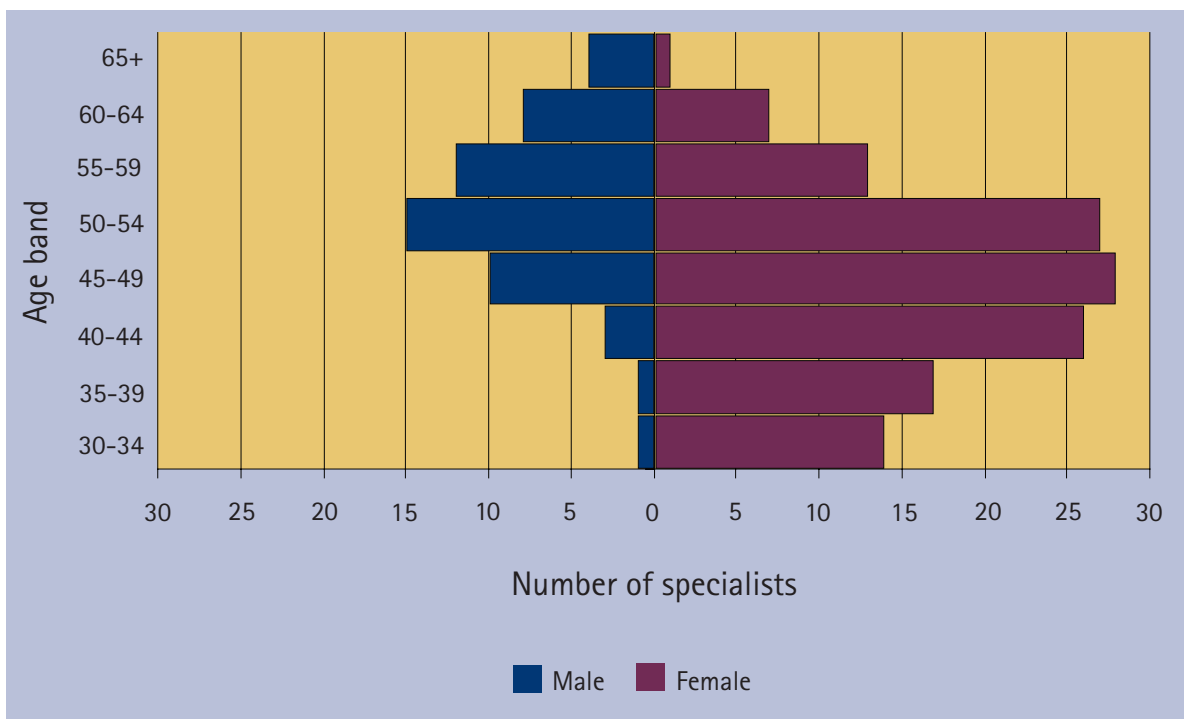

Fig. 1 Number of UK specialists by age group and gender

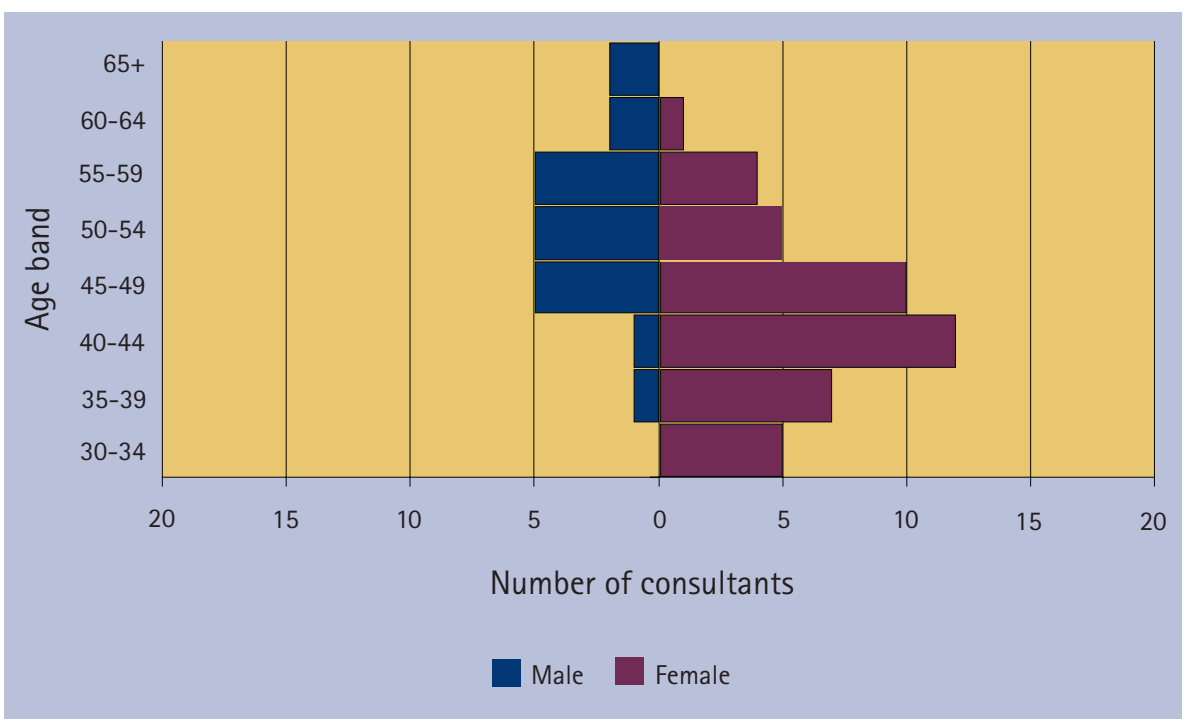

Fig. 2 Number of UK consultants by age group and gender

either already retired or were currently working overseas. This paper is, therefore, based on a sample of 187 specialists in paediatric dentistry (54 (28.9\%) male and 133 (71.1\%) female). Figure 1 presents data relating to the number of specialists by age-group and gender. As the sample included a subset comprising
65 individuals (21 (32.3\%) male and 44 (67.7\%) female) holding consultant contracts, analogous data for this group are presented in Figure 2.

The majority of specialists (138) stated that they practised in England; 27 respondents were located in Scotland, 12 in Northern Ireland and 9 in Wales. To provide 
further clarity, respondents practising in England also stated to which postgraduate dental deanery they were related. Here, considerable geographical imbalance was noted, with $60 \%$ of specialists practising in England being based around just three of the ten deaneries (London (46), North West (20) and Yorkshire and Humber (17)). Among those specialists holding consultant contracts, 46 were based in England, 13 in Scotland, 4 in Wales and 2 in Northern Ireland.

The majority of respondents (120) reported that they worked in a hospital setting, with 74 working in salaried primary care services and 16 working in specialist practice. Answers to this question, however, were not mutually exclusive; 17 respondents practised in hospital/salaried primary care settings, 6 in hospital/specialist practice, 2 in specialist practice/salaried primary care and 1 in all three settings.

One hundred and eighty-two respondents provided data relating to their working pattern. One hundred respondents (40 males and 60 females) reported that they were working full-time and 82 (14 males and 68 females) part-time. To provide further clarity, 73 of those working parttime included data relating to the number of sessions worked per week; this group of respondents worked a mean of 5.75 sessions per week (range 1-9).

One hundred and eighty-six respondents provided data relating to career breaks. Of these, 57 ( 5 males and 52 females) indicated that they had already taken a break from practice at some time during their career, though the frequency and length of such breaks was not recorded. Thirty-three respondents who had previously taken a career break indicated that they were now working on a part-time basis. To provide further clarity, 30 of these included data relating to the number of sessions worked per week; this group of respondents worked a mean of 5.2 sessions per week (range 1-9). Ten of the 129 respondents who had not taken a career break at the time of the study indicated that they intended taking a career break at some time in the future.

One hundred and eighty-six respondents provided data regarding their planned retirement dates; these, together with analogous data relating to the 65 consultants in paediatric dentistry, are presented in Table 1.

\section{DISCUSSION}

From the data presented here, it can be seen that, in the UK, the provision of specialist services in paediatric dentistry already relies upon a workforce that is feminised. From Figure 1, however, it is clear that this current gender imbalance will only become more pronounced over time, more women than men having entered the specialty in recent years. Of those existing specialists under the age of 50 years, only 15\% are male; likewise, at the time that his survey was carried out, only $5(16.7 \%)$ of 30 pre-CCST trainees were male (source: SAC data). Hence, as those aged over 50 (where males constitute $44.9 \%$ of the workforce) retire, there will be a dramatic rise in the proportion of specialists who are women. This latter observation should come as no surprise as by the end of the 20th century, 50\% of all new entrants to undergraduate dental courses were female; ${ }^{2}$ neither is the observation restricted to the specialty of paediatric dentistry, the same trend towards feminisation having already been noted in the orthodontic workforce. ${ }^{3}$

The observed change in gender balance has a number of important implications. Within any workforce, different working patterns (full- or part-time working) exhibited by different groups are important as they determine the total volume of activity undertaken. In this survey, 45\% of responding specialists indicated that they were currently working part-time. When broken down by gender, however, it can be seen that $53 \%$ of females were working part-time compared with $26 \%$ of males. This finding is in agreement with previous published research that has shown that women follow a different work pattern to their male counterparts and are more likely to take career breaks and work part-time after they have children. ${ }^{4,5}$ It follows, therefore, that as more women enter the profession the available number of specialist sessions will reduce.

In an examination of the implications for the dental workforce of a greater role for women, Newton and co-workers ${ }^{6}$ reported that around $60 \%$ of female and $30 \%$ of male dentists in the UK took a career break, with women taking longer career breaks than men. This practice has two implications: firstly, the individual's working life is reduced as a direct result of taking a career break; secondly, career breaks have been associated with shorter working hours on return to the profession. Indeed, Newton and co-workers calculated that female dentists who take a career break have a working life approximately 25\% shorter than dentists who do not take a career break. In the present study, the percentage of specialists taking career breaks was somewhat lower than that observed by Newton and co-workers, $9.2 \%$ of males and $39.1 \%$ of females already having taken a break from practice at some time during their career. It may be that, having devoted a significant amount of time to postgraduate training, specialists are less likely to take a career break than general dental practitioners. The authors consider it regrettable that information was not sought in relation to either the frequency or length of career breaks or the reason for which they were taken. It is recommended that this omission be rectified in any future research in this field.

Retirement is the single most important cause of loss of workforce to the profession; variation in retirement age is, therefore, an important consideration. In a recent study conducted in New Zealand, Ayers and co-workers ${ }^{5}$ reported that two-thirds of women and one-third of men planned to retire from dentistry before 60 years of age. While, in the UK, the recent increase in the minimum retirement age from 50 to 55 years has the potential to affect the size of the workforce, its impact cannot yet be quantified. What is clear, however, is that $84(45.2 \%)$ responding specialists plan to retire during the next ten years and the fact that many of those considering retirement are men is likely to further impact on longer term workforce issues. ${ }^{6}$ In addition, although specific data were not collected here, it can be speculated that a significant number of those considering retirement will consciously reduce their working hours before retiring, thus bringing the impact on availability of specialist services forward in time.

The above trends are mirrored in the subset of specialists holding consultant contracts. Of those existing consultants aged under 50 years, only seven (17.1\%) are male; at the time that this survey was carried out, only two (9.1\%) of the 22 post-CCST trainees were male. Hence, as 
those aged over 50 (where males constitute $58.3 \%$ of the consultant workforce) retire, there will be a dramatic rise in the proportion of women in the most senior positions in the specialty. Though not investigated in the present study, experience has shown that, by the time they complete training early in their third decade, female trainees tend to be geographically tied (through having established domestic commitments). In recent years, this has led to difficulties in filling some consultant posts. Recognising the problems associated with part-time training, subsequent part-time working and geographic immobility, the SAC in Paediatric Dentistry has, in recent years, encouraged an increase in the availability of opportunities for individuals to undertake post-CCST training.

At the time that this survey was carried out, there were 30 pre-CCST trainees (source: SAC data). While retention of this number of training posts should be sufficient to maintain the current size of the Specialist List, the trends observed in the data presented here indicate that simply maintaining the number of registered dentists on the Specialist List in Paediatric Dentistry may be inadequate to maintain the current volume of provision of specialist services. It is, therefore, imperative that workforce planning takes account of part-time working and, indeed, part-time training.

The forgoing discussion must be considered in the context of the adequacy or otherwise of the current provision of specialist services in paediatric dentistry. The British Society of Paediatric Dentistry's publication 'Consultants and specialists in paediatric dentistry" suggests that, based on referral data, approximately $1 \%$ of a child population needs to see a paediatric dentist in any one year; it concludes that one specialist in paediatric dentistry is needed for every 20,000 children. In mid-2008, there were approximately $11,517,300$ children aged under 16 years in the United Kingdom. ${ }^{8}$ On the basis of the forgoing, manpower planning should aim to provide approximately 576 specialists in paediatric dentistry, more than double the number available at the time of this survey. Consideration should also be given to the current geographic imbalance, children in large areas of the UK either having no access to such specialist services or having to travel considerable distances to access them.

\section{CONCLUSIONS}

Working patterns associated with a workforce in which women play a greater role will have a considerable impact on the volume of service that can be provided. Workforce planners must be cognisant of the need to increase the number of specialists in training to take account of extended training times and service lost through part-time working and career breaks.

The authors wish to acknowledge the assistance of Dr Nigel Blewitt, Research Associate in Dental Public Health, Cardiff University School of Dentistry in generating Figures 1 and 2.

1. General Dental Council. Annual review 2008. London: GDC, 2009. http://www.gdc-uk.org/ NR/rdonlyres/D5E6F630-4E45-42E3-A607648A27EBDAA9/0/AnnualReview08web.pdf.

2. Seward M. The gender challenge. Br Dent J 2000; 189: 525.

3. Murphy T C, Parkin N A, Willmot D R, Robinson P G The feminisation of the orthodontic workforce. Br Dent J 2006; 201: 355-357.

4. Stewart F M, Drummond J R, Carson L, HoadReddick $\mathrm{G}$. The future of the profession - a survey of school applicants. Br Dent J 2004; 197: 569-573.

5. Ayers K M, Thomson W M, Rich A M, Newton J T. Gender differences in dentists' working practices and job satisfaction. J Dent 2008; 36: 343-350.

6. Newton J T, Buck D, Gibbons D E. Workforce planning in dentistry: the impact of shorter and more varied career patterns. Community Dent Health 2001; 18: 236-241.

7. British Society of Paediatric Dentistry. Consultants and specialists in paediatric dentistry. Available online at http://www.bspd.co.uk/publication-23.pdf (accessed 24 February 2010)

8. Office for National Statistics. Population estimates for UK, England and Wales, Scotland and Northern Ireland - current datasets. http://www.statistics.gov. uk/statbase/Product.asp?vInk=15106 (accessed 24 February 2010). 